\title{
De Italo Calvino a Ricardo Piglia, do centro para a margem: o deslocamento como proposta para a literatura deste milênio
}

\author{
Renato Cordeiro Gomes
}

para o Edson

Já é certamente lugar comum nos estudos literários e nos estudos culturais (ou, se quisermos, nos estudos de crítica cultural) lançar mão das oposições centro/margem, centro/ periferia, cosmopolitismo/nacionalismo, global/local, bem como das categorias de diáspora, deslocamento, desterritorialização e tantas outras. Mesmo quando esses estudos são acusados de mais uma vez se colocarem na absorção de teorias geradas nos centros hegemônicos, para dar conta de fenômenos de culturas periféricas e dependentes. Gostaria, então, desde já, de adotar o deslocamento desse tipo de pensamento, a fim de trazer a esta praça de convites (para usar uma imagem de Drummond) uma outra proposta vinda justamente da margem, que elege o "deslocamento" como estratégia discursiva e ideológica para tentar enfrentar a crise da literatura no mundo contemporâneo, equacionando a literatura do futuro e o futuro da literatura, neste conturbado tempo pós-utópico que inaugura o século XXI.

Refiro-me ao ensaio "Una propuesta para el nuevo milenio", de Ricardo Piglia. Publicado no segundo número do Caderno de Cultura Margem/Márgenes ${ }^{1}$ (outubro de 2001),

${ }^{1}$ Uma revista que falasse a partir das margens, que procedesse, então, a um deslocamento em relação aos centros hegemônicos. Essa é a proposta de criação de Margens/Márgenes, revista cujo projeto partiu da idéia do escritor Ricardo Piglia, por ocasião de um encontro com as professoras Monica Bueno (Universidad de Mar del Plata) e Maria Antonieta Pereira (Universidade Federal de Minas Gerais). A proposta foi concretizada num projeto desenvolvido com o apoio da Fundação Rockefeller. A revista, que tem como editor Silviano Santiago e como editores-assistentes Wander Mello Miranda e Florencia Garramuño, e que pretende, em primeira instância, ser viabilizada a partir de pesquisas desenvolvidas principalmente fora das grandes metrópoles da Argentina e do Brasil, propõe-se a formalizar o intercâmbio entre esses dois países, com o propósito de "discutir as 
(Piglia, Ricardo. Tres pro. puestas para el próximo mi Puio - y cinco dificultades. tura Económica, 2001.) mas escrito um pouco antes, o ensaio elege como idéia central o que chama de desplazamiento, distancia, cambio de lugar, o que significa "sair do centro, deixar a linguagem falar também das bordas, no que se ouve, no que chega de outro”. Esse núcleo é retomado e ampliado na conferência apresentada em Cuba, na Casa de las Américas, em 2000, que constitui o pequeno livro Tres propuestas para el próximo milenio y cinco dificultades*, publicado em 2001 pela editora Fondo de Cultura Económica.

Por um jogo de imaginação, essas propostas viriam completar, de um ponto de vista da margem, as que Italo Calvino formulara em Seis propostas para o próximo milênio, exatamente a sexta das "lições americanas" que o escritor italiano leria na Universidade de Harvard, mas que não tivera tempo de escrever. Então, entre os valores ou as qualidades que a literatura deveria conservar ou que deveriam persistir no futuro, "para tornar possível uma melhor percepção da realidade, uma melhor experiência com a linguagem”*, Calvino, como sabemos todos, elege a leveza, a rapidez, a exatidão, a visibilidade, a multiplicidade, valores que ele consignava para a literatura deste milênio e deixa como seu testamento literário. O escritor argentino se propõe a escrever a sexta, não a consistência, cogitada por Calvino, mas o deslocamento. Formula Piglia:

Cómo poderíamos nosotros considerar ese problema desde Hispanoamérica, desde la Argentina, desde Buenos Aires, desde un suburbio del mundo. Cómo veríamos nosotros el problema del futuro de la literatura y de su función. No cómo lo ve alguien en un país central con una gran tradición cultural. Nos planteamos entonces ese problema desde el margen, desde
Como poderíamos considerar esse problema do ponto de vista da América Hispânica, da Argentina, de Buenos Aires, de um subúrbio do mundo. Como veríamos o problema do futuro da literatura e de sua função. Não como o vê alguém em um país central com uma grande tradição cultural. Propomos então esse problema a partir da margem, da

perspectivas transnacionais contemporâneas relativas a literatura, cultura, artes e política, a partir das margens e do local, organizando um espaço de escrita e reflexão que fosse, na sua excentricidade histórica e geográfica, metonímia da condição sociocultural periférica no atual processo de mundialização da economia”. Depois de ser um Caderno de Cultura, de que foram publicados dois números, o projeto concretizou a revista propriamente dita. 
el borde de las tradiciones centrales, mirando al sesgo. Y este mirar al sesgo nos da una percepción, quizás, diferente, específica.* borda das tradições centrais, olhando de viés. E este olhar de viés nos dá uma percepção, talvez, diferente, específica.

A partir dessa tomada de posição, o escritor argentino procura ver as vantagens que não estar no centro às vezes proporciona. Em seu exercício de ficção especulativa, busca imaginar esse valor suplementar (as vantagens de estar na margem) que poderia persistir na literatura do futuro, de uma literatura potencial, o que envolveria inferir a realidade que essa literatura postula. Para imaginar esse mundo alternativo, evoca a noção de começo, de algo que abre caminho, numa perspectiva que se ancora em outro lugar (a margem). A pergunta sobre a literatura do futuro, por conseguinte, é também uma pergunta sobre o limite. A questão, como pondera Piglia, talvez se deva ao fato de que escrever da Argentina leva os escritores a confrontarem-se com os limites da literatura, o que implica refletir sobre os limites que a linguagem impõe, quando se fala de algo que está além da linguagem (como o horror, a violência), que aquele que fala não consegue fazer significar.

Desse modo, se a primeira proposta tem a ver com a noção de verdade como horizonte político e objeto de luta, a segunda está ligada à noção de limite, isto é, à impossibilidade de expressar diretamente essa verdade. Tomando como exemplo o conto "Esa mujer" (1963), de Rodolfo Walsh², sobre alguém que está procurando o cadáver de Eva Perón, que nunca é nomeada diretamente, mas é o que move o relato, demonstra Piglia que o cadáver desaparecido condensa a

${ }^{2}$ Piglia elege a figura de Rodolfo Walsh como uma síntese do que, para ele, seria a tradição da política hoje na literatura argentina: "um grande escritor e ao mesmo tempo alguém que, como muitos outros em nossa história, levou ao limite a noção de responsabilidade civil do intelectual". Assim nos apresenta Walsh: "começou escrevendo contos policiais à maneira de Borges e publicou um dos grandes textos de literatura documental da América Hispânica: Operación masacre; paralelamente escreveu uma série de relatos curtos e por fim. como ato do movimento de resistência clandestina à ditadura militar, escreveu e distribuiu no dia 24 de março de 1977 esse texto único que se chama "Carta abierta de un escritor a la Junta Militar". Foi assassinado no dia seguinte em uma emboscada. Sua casa foi arrasada e seus manuscritos, seqüestrados e destruídos pela ditadura" (Piglia, Ricardo. Tres propuestas para el próximo milenio - y cinco dificultades. Ob. cit.: 14-5). 
"(Piglia, Ricardo, "Una propuesta para el nuevo mile nio", Margens/Márgenes, $\mathrm{n}$. 2. Belo Horizonte, Mar De Plata, Buenos Aires, out. 2001:3.)

"existe una verdad de la his toria y esa verdad no es di. recta, no es algo dado, sur. ge de la lucha y de la con. frontación y de las relacio. nes de poder" (Piglia, Ricar do. Tres propuestas para e próximo milenio - y cinco di ficultades. Ob. cit.: 30.) tensão entre o mundo do letrado, do intelectual, e o mundo popular, o mundo do outro. Afirma ele que há uma estratégia de "deslocamento": atribuir a outro uma cena que condensa e cristaliza uma rede múltipla de sentidos, indo além da mera informação, uma vez que é um movimento interno ao relato que desloca para o outro a verdade da história, verdade que tem a estrutura de uma ficção na qual outro fala, isto é, propõe-se a construir na linguagem um lugar para que outro possa falar. "A literatura seria o lugar no qual sempre é o outro que vem a dizer. Yo soy outro, como dizia Rimbaud [lembre-se que a frase do poeta francês é "Je est un autre"]. Sempre há outro aí. Esse outro é o que há de saber ouvir para que o que se conta não seja mera informação e tenha a forma da experiência”, completa Piglia no pequeno ensaio que antecedeu à conferência de Havana. Neste ensaio, há um outro exemplo de Walsh, "Carta a Vicky", em que conta a morte da filha, que lhe é revelada através da visão de outro. O grande escritor argentino escolhe essa visão mediada para contar uma experiência extrema e transmitir um acontecimento impossível; dá para isso, portanto, a palavra ao outro, um desconhecido que fala de sua dor. E assim, com esse deslocamento, pode chegar a contar esse ponto cego da experiência que quase não se pode transmitir.*

Ao privilegiar el desplazamiento, la distancia, como traço fundamental para a literatura do próximo milênio (em que já estamos), o escritor argentino quer, ao fim a ao cabo, discutir o lugar do intelectual e do escritor, a sua responsabilidade civil, e o futuro da literatura e as relações entre ela e a política: "existe uma verdade da história e essa verdade não é direta, não é algo dado, surge da luta e do confronto e das relações de poder"*. Requer, então, o deslocamento da observação direta da realidade, para reivindicar a visão indireta, mediada por outro, por outras imagens, para se contrapor às ficções oficiais, às ficções do Estado. Para Piglia, a relação entre a literatura - entre o romance, escritura ficcional - e o Estado é uma relação de tensão entre dois tipos de narração, pois o Estado também narra, também ele constrói ficções, também manipula certas histórias. A literatura, por seu turno, constrói relatos alternativos, em tensão com esse relato construído e difundido pelo Estado*. 
A proposta do autor de Respiração artificial funciona também como estratégia por meio da qual se percebem continuidades e mudanças nos contatos entre matrizes locais que ressaltam a margem e "abalam", em graus diversos, as matrizes dadas como universais pelo projeto expansionista do Ocidente. As excentricidades históricas e geográficas de que fala Piglia são, pois, deslocamentos estratégicos, distâncias (certamente ecoa aqui o efeito de distanciamento de Brecht, de quem Piglia retoma as "cinco dificuldades" para expressar a verdade, aludidas nos parênteses do título e que remetem ao sentido político e crítico que quer resgatar para a literatura deste milênio), que permitem um olhar enviesado, tornando possível medir diferentes direções e velocidades: o espaço e o tempo numa concepção que não ignora o que foi transmitido ou imposto pelo poder hegemônico, pelo Estado, e possibilita gerar descontinuidades, cortes, desvios, para além de uma relação causalista e linear dada como hegemônica.

$\mathrm{O}$ deslocamento enquanto idéia regeneradora da margem pode, assim, ser privilegiado como estratégia operacional fecunda para a literatura e as culturas não hegemônicas, dentro de determinado contex to histórico, uma vez que o conceito de hegemonia nunca é um estado permanente e nunca é indiscutível, como lembra Stuart Hall*. Tal estratégia de que a cultura da margem lança mão para resistir à sua conformação passiva ao modelo, à imposição da cópia, da semelhança (o fazer igual), possibilita a assunção de produtos culturais periféricos que, em diálogo e em tensão permanente (interna e externamente), podem fecundar a produção artística dos centros hegemônicos. As excentricidades históricas e geográficas não podem, entretanto, estar dissociadas dos deslocamentos discursivos, atrelando-se, por outro lado, a marcas identitárias que a periferia constrói para si num processo permanente, ao transformar uma provável identidade estável e seu caráter essencialista numa identidade em processo, o que se torna uma urgência em tempos de globalização econômica e homogeneização cultural.

Desse modo, parece que as propostas de Piglia são pertinentes para um tempo em que a assunção das diferenças (não somente das diversidades) e as reivindicações a elas referentes, bem como a desterritorialização, ao lado de deslocamen- 
"(Bhabha, Homi. O local da cultura. Belo Horizonte: Ed. UFMG, 1998: 300.)

(Em: Santiago, Silviano. Uma literatura nos trópicos. São Paulo: Perspectiva, 1978.) tos cada vez mais intensos, por razões diversas (das migrações ao turismo, passando pelos êxodos, pelas diásporas), abalam a conjuntura específica de identidade, locação e locução da cultura, que tem por base uma determinação estável e apresentável de uma localidade, isto é, que traz as marcas identitárias fornecidas pela permanência, pela continuidade, pela tradição, portanto. Essa realidade pós-moderna do desenraizamento das formas espaciais e temporais e dos homens cria espaços com limites indeterminados e irregulares entre e dentro de culturas, como vem estudando Homi Bhabha.

O deslocamento, que pode ser entendido como espacialgeográfico, ou temporal, ou discursivo, associa-se à noção de limite de que fala Piglia, passível de ser conjugada à problemática da fronteira, que por sua vez implica a noção de transgressão (e vice-versa). Por essa ótica, como postula Homi Bhabha, as narrativas legitimadoras da dominação cultural ainda estruturadas numa lógica binária de centro e periferia, hierarquizadora e eurocêntrica, podem ser deslocadas para revelar o que ele chama "terceiro espaço", em que convivem momentos diferentes do tempo histórico. Ou, dito com outras palavras, "a temporalidade não-sincrônica das culturas nacional e global abre um espaço cultural - um terceiro espaço - onde a negociação das diferenças incomensuráveis cria uma tensão peculiar às existências fronteiriças"**. Essa concepção está bem próxima do conceito de entrelugar, formulado por Silviano Santiago no ensaio "O entrelugar do discurso latino-americano"*, de 1971, quando, motivado pelas teorias da dependência, procura uma metodologia de leitura para o lugar de transgressão das literaturas produzidas nos trópicos. A astúcia do olhar periférico, olhar enviesado, que avalia a dependência cultural para além do econômico, não para negá-la, mas como atitude afirmativa capaz de autoconhecer-se como valor diferencial. Um pé lá, outro cá, num entre-lugar, lugar diferido; pensa-se uma cultura e uma literatura do ponto de vista de uma província ultramarina ou dos subúrbios da periferia (para usar a imagem de Piglia), reformulando conceitos etnocêntricos, debilitando esquemas cristalizados de unidade, pureza e autenticidade. Esse descentramento desloca a cultura européia de seu lugar privilegiado de cultura de referência - postura inspirada em 
Derrida - e põe em causa a descolonização dos pensamentos brasileiro e latino-americano. Transmutação dos valores, que o contato entre culturas diferentes provoca. Entre assimilação e agressividade, aprendizagem e reação, obediência e rebelião, realiza-se “o ritual antropofágico da cultura latinoamericana”, aquele que se faz de temporalidades disjuntivas, múltiplas e tensas, temporalidade de entrelugar, que desestabiliza o significado da cultura nacional como homogênea, pois é uma cultura dividida no interior dela própria, articulando sua heterogeneidade e seu hibridismo*.

Se não há referência direta a essas questões no ensaio de Piglia, elas estão na deriva do que aí é postulado e permitem outras indagações. Como construir na linguagem o lugar em que o outro possa falar? Como transfigurar e conciliar nos discursos das artes, da literatura e das mídias diferentes direções e temporalidades?

É na busca de equacionar questões desse tipo que o ensaio de Ricardo Piglia é fecundo, ao elaborar as suas três propostas para o próximo milênio. Ao lado do desplazamiento e da noção de limites da literatura, ou seja, "um deslocamento para o outro, um movimento ficcional para uma cena que condensa e cristaliza uma rede múltipla de sentido"*, o escritor argentino requer a claridade da linguagem como virtude (essa é a terceira proposta). Há um ponto extremo ao que parece impossível de acercar-se, como se a linguagem tivesse uma margem, como se fosse um território com uma fronteira, depois da qual estão o deserto infinito e o silêncio, num tempo que dá as boas-vindas ao "deserto do real" (a expressão é do filme Matrix, dos irmãos Wachowski, de 1999). Acrescenta ele: "Em momentos em que a língua se tornou opaca e homogênea, o trabalho detalhado, mínimo, microscópico da literatura é uma resposta vital [...]: uma luta contra os estereótipos e as formas cristalizadas da língua social"*.

Com a mediação dessas estratégias políticas, éticas e discursivas, Piglia busca resgatar a função utópica da literatura. A literatura seria um antídoto contra a peste da linguagem (de que fala Ítalo Calvino, ao discorrer sobre a "exatidão”), que faz repetir e modular as construções monolíticas da realidade e se relaciona à língua técnica, demagógica, publicitária que a sociedade impôs. Seus argumentos estão bem próximos da proposta de Ítalo Calvino, ao falar do excesso
"(Bhabha, Homi. O local da cultura. Ob. cit.: 209 .)

"un desplazamiento para e otro, un movimiento ficcio. nal hacia una escena que condensa y cristaliza una red múltiple de sentido" (Piglia, Ricardo. Tres pro. puestas para el próximo mi. lenio - y cinco dificultades. Ob. cit.: 35.6.)
" En momentos en que la lengua se ha vuelto opaca y homogénea, el trabajo deta. llado, mínimo, microscópi. co de la literatura es una respuesta vital [...]: una lu. cha contra los estereótipos y las formas cristalizadas de la lengua social" (: 41 .). 
"(Calvino, Ítalo. Seis propos. tas para o próximo milênio. São Paulo: Companhia das Letras, 1990: 107.) de imagens no mundo contemporâneo. Afirma ele: "Hoje somos bombardeados por uma tal quantidade de imagens a ponto de não podermos distinguir mais a experiência direta daquilo que vimos há poucos minutos na televisão"*. A advertência contra o excesso que esvazia a experiência é, entretanto, contrabalançada pelo que o escritor italiano propõe como uma "pedagogia da imaginação", que possibilitaria recuperar certa essencialidade da imagem, através de procedimento que levaria a "reciclar as imagens usadas, inserindoas num contexto novo que lhe mude o significado"*. Procura ressaltar a relação de dupla implicação entre a expressão verbal e a imagem, em um jogo que dê conta dos processos imaginativos da criação. Busca ver o que há de imagem na palavra e o que há de palavra na imagem, mas não se trata de encontrar os processos interativos entre palavra e imagem; propõe a visibilidade enquanto um meio transparente, através do qual a realidade se apresenta à compreensão. Cito:

Penso numa possível pedagogia da imaginação que nos habitue a controlar a própria visão interior sem sufocá-la e sem, por outro lado, deixá-la cair num confuso e passageiro fantasiar, mas permitindo que as imagens se cristalizem numa forma bem definida, memorável, auto-suficiente, icástica.*

Essa inflação é redita algumas vezes, em outros termos, a exemplo de quando formula a idéia de "uma superabundância imagética", ou seja, "o dilúvio das imagens pré-fabricadas que inundam a humanidade"*. Afirma o escritor italiano: "em nossa memória se depositam, por estratos sucessivos, mil estilhaços de imagens, semelhantes a um depósito de lixo, onde é cada vez menos provável que uma delas adquira relevo"*.

Como contraponto desse estado de coisas, Calvino formula a proposta da "exatidão". Para ele, "exatidão quer dizer principalmente três coisas: 1) um projeto de obra bem definido e calculado; 2) a evocação de imagens visuais, incisivas, memoráveis, 'icásticas'; 3) uma linguagem que seja a mais precisa possível como léxico e em sua capacidade de traduzir as nuanças do pensamento e da imaginação"*. O que lhe parece óbvio tem a ver com sua ojeriza pessoal da linguagem usada de modo aproximativo, casual, descuidado. Tal aspecto leva Calvino a formular sua teoria da "peste da linguagem" e também das imagens: 
Às vezes me parece que uma epidemia pestilenta tenha atingido a humanidade inteira em sua faculdade mais característica, ou seja, no uso da palavra, consistindo essa peste da linguagem numa perda de força cognoscitiva e de imediaticidade, como um automatismo que tendesse a nivelar a expressão em fórmulas mais genéricas, anônimas, abstratas, a diluir os significados, a embotar os pontos expressivos, a extinguir toda centelha que crepite no encontro das palavras com novas circunstâncias.*

Todo esse estado de coisas seria o contrário da "exatidão", objeto do culto de Calvino. E é por esse viés que denuncia a peste da linguagem e aponta o antídoto.

Não me interessa aqui indagar se as origens dessa epidemia [que ele estende ao universo das imagens] devam ser pesquisadas na política, na ideologia, na uniformidade burocrática, na homogeneização dos mass-media ou na difusão acadêmica de uma cultura média. O que me interessa são as possibilidades de salvação. A literatura (e talvez somente a literatura) pode criar anticorpos que coíbem a expansão desse flagelo lingüístico."

E completa, ao constatar que a inconsistência advinda do vírus está no próprio mundo: "Meu mal-estar advém da perda de forma que constato na vida, à qual procuro opor a única defesa que consigo imaginar: uma idéia da literatura"*. A própria ficção de Calvino prova isto: Palomar e $A s$ cidades invisiveis, por exemplo.

Como vimos, proposta semelhante é a formulação de Ricardo Piglia, que busca recuperar resíduos utópicos da literatura. $\mathrm{O}$ escritor argentino fala então no paradoxo da língua privada da literatura, rastro mais vivo da linguagem social. A intervenção política do escritor se define, antes de tudo, na confrontação com os usos oficiais da linguagem, naquilo que ele chama de "ficções oficiais". Nesse sentido é que denuncia a obscuridade deliberada da linguagem convertida em território ocupado, a que se opõe, justamente, a claridade como virtude, que possibilita à literatura minar as ficções do Estado, criando as contraficções, que são ficções também, mas com outro valor estético, necessariamente atrelado ao ético e ao político, porque capaz de dar a ver, ou instaurar, a possível "verdade", embaralhada nos relatos oficiais.

Não é à toa que, ao findar sua conferência em Havana, evoque as "cinco dificuldades para escrever a verdade" re- 
queridas por Brecht. São elas: ter a coragem de escrever a verdade; ter a inteligência de reconhecer a verdade; possuir a arte de tornar a verdade manejável como uma arma; ter a capacidade de escolher aqueles em cujas mãos a verdade se torna eficiente; ter a astúcia de divulgar a verdade entre muitos, de difundi-la. Assim, o escritor argentino postula um modo de imaginar as possibilidades de uma literatura futura ou as possibilidades futuras da literatura.

As propostas de Italo Calvino e de Ricardo Piglia, ao contraporem-se ao excesso que eles ligam a uma espécie de vírus que ataca a linguagem, procuram, de certa forma, resgatar determinados valores da literatura, enquanto uso social da linguagem, para devolver-lhe a função utópica que perdeu com a pós-modernidade. Discutem, ao fim e ao cabo, valores da literatura e da linguagem em seu caráter ético e político, que eles agregam ao estético, que não vale como essência absoluta fora da história. A estratégia político-discursiva do escritor argentino, todavia, ganha um valor suplementar, qual seja, postula um lugar da enunciação, de forma nenhuma neutro: a margem, as bordas das tradições hegemônicas, de fora do poder, lugar estratégico que o intelectual e escritor escolhe para combater as ficções do Estado. Estratégia mais contundente em se tratando de literaturas latino-americanas, aquelas produzidas nos subúrbios do mundo.

Parece que os dois escritores, ao combater o excesso da linguagem que caracterizaria o mundo contemporâneo, apontam para o paradoxo da arte deste início de milênio. Se o excesso desgasta a mensagem e a verdade, por outro lado abre possibilidades de reinvenção, mas denunciam uma determinada economia política do signo, que se acomoda e incentiva a inflação dos signos e das imagens.

Gostaria de terminar, citando mais uma vez Ricardo Piglia, com as palavras com que fecha o seu pequeno ensaio "Una propuesta para el nuevo milenio" (sintomaticamente, publicado num caderno de cultura denominado Margens/ Márgenes), que antecedeu a conferência sintomaticamente proferida na Casa de las Américas e publicada no n. 222 (janeiro-março de 2001) da revista dessa instituição cubana. Cito: 
En el año de 2100, cuando el nombre de todos los autores se haya perdido y la literatura sea intemporal e anónima, esta pequeña propuesta sobre el desplazamiento y la distancia, será, tal vez, un apéndice o una intercalación apócrifa en un website llamado Las seis propuestas, que para ese entonces serán leídas como se fueran consignas en un antiguo manual de estrategia usado para sobrevivir en tiempos difíciles.
No ano de 2100, quando o nome de todos os autores estiver perdido e a literatura for intemporal e anônima, esta pequena proposta sobre o deslocamento e a distância será, talvez, um apêndice ou uma intercalação apócrifa em um website chamado As seis propostas, que para esses tempos serão lidas como se fossem registros em um antigo manual de estratégia usado para sobreviver em tempos difíceis. 


\section{Renato Cordeiro Gomes}

Doutor em Letras pela Pontifícia Universidade Católica do Rio de Janeiro, onde é professor Associado do Departamento de Comunicação Social e do Programa de Pós-Graduação em Letras do Departamento de Letras. Pesquisador do CNPq. Coordenador do Programa de Pós-Graduação em Comunicação da PUC-Rio. Coordenador-Adjunto da Cátedra Padre Antônio Vieira de Estudos Portugueses da PUCRio, em convênio com o Instituto Camões. Publicou Todas as cidades, a cidade (Rio de Janeiro: Rocco, 1994) e João do Rio: vielas do vício, ruas da graça (Rio de Janeiro: Relume-Dumará, 1996); organizou o volume Marques Rebelo da Coleção Melhores Crônicas (São Paulo: Global, 2004). Entre seus últimos ensaios publicados, destacam-se "Que faremos com esta tradição? Ou: relíquias da casa velha”. (Em: Margato, Izabel (org.). Figuras da lusofonia: Cleonice Berardinelli, 2002); "Literatura e resíduos utópicos: heterogeneidade cultural e representações da cidade" (Em: Schollhammer, Karl Eric e Olinto, Heidrun Krieger (org.). Literatura e cultura, 2003).

Palavras-chave Italo Calvino Ricardo Piglia deslocamento distância margem futuro da literatura

Key words Italo Calvino Ricardo Piglia dislocation dislocation distance literature's future

Palabras-llave Italo Calvino Ricardo Piglia desplazamiento distancia margen futuro de la literatura

\section{Resumo}

O escritor italiano Italo Calvino deixou como testamento literário seis propostas que caracterizariam a literatura do "próximo milênio", mas não teve tempo de redigir a sexta dessas propostas, justamente a "consistência”. O escritor argentino Ricardo Piglia, na conferência "Três propostas para o próximo milênio (e cinco dificuldades)”, proferida na Casa de las Américas, Cuba, em 2000, propõe, então, escrevê-la, não a consistência, mas o "deslocamento, a distância”, para equacionar o problema do futuro da literatura e sua função na sociedade, vista, entretanto, a partir da margem, das bordas das tradições centrais da América Hispânica.

\section{Abstract}

The Italan writer Italo Calvino has left as his literary legacy the six proposals that would characterize the literature of the "next millenium", but he had no time to write "consistency", the sixth of these proposals. The Argentinian writer Ricardo Piglia at the "Three proposals for the next millenium (and five difficulties)", conference held at "Casa de las Américas”, Cuba, in 2000, proposes, therefore, to write the
\end{abstract}

\section{Resumen}

El escritor italiano Italo Calvino ha dejado como testigo literario seis propuestas para caracterizar la literatura del "próximo milenio", pero no tuvo tiempo de escribir la sexta, justo la que llevaria el nombre de "consistencia". El escritor argentino Ricardo Piglia en su conferencia "Tres propuestas para el próximo milenio (y cinco dificultades)", hecha en la Casa de Las Américas, Cuba, año 2000, intenta escribirla - no 
proposals "dislocation" and "distance" in the place of consistency, aiming at solving the problem of literature's future and its role in society, which is seen, however, from the edge, from the border of Spanish America's central traditions. como consistencia - sino como “desplazamiento, distancia”, para equacionar el problema del futuro de la literatura y su función en la sociedad, pero desde el margen, desde el borde de las tradiciones centrales de HispanoAmérica.
Recebido em 30/09/2003

Aprovado em 30/11/2003 